\title{
Notes on the Reproductive Biology of the Greater Green Snake, Cyclophiops major (Günther, 1858), in Taiwan
}

\author{
Simon Dieckmann ${ }^{1}$, Gerrut Norval ${ }^{2 *}$, and Jean-Jay $\mathrm{Mao}^{3}$ \\ ${ }^{1}$ No. 430 Huacheng 5th Str., Ji-an Township, Hualien County, 973, Taiwan, R.O.C. (gujonaan@yahoo.de) \\ ${ }^{2}$ Applied Behavioural Ecology \& Ecosystem Research Unit, Department of Environmental Sciences, \\ UNISA, Private Bag X6, Florida, 1710, Republic of South Africa (gnorval@gmail.com) \\ ${ }^{3}$ Department of Forestry and Natural Resources, National Ilan University. No. 1, Sec. 1, Shen-Lung Rd., Ilan, 260, Taiwan, R.O.C. (jjmao@niu.ede.tw) \\ *corresponding author
}

$\mathrm{T}$ he Greater Green Snake (Cyclophiops major [Günther, 1858]; Fig. 1) has a natural distribution that extends from parts of Vietnam through Laos, parts of China, and Taiwan (Pope 1935, Kuntz 1963, Orlov et al. 2000). In Taiwan, C. major is fairly common and tends to inhabit grassy and wooded foothill and montane areas (Kuntz 1963, Lue et al. 2002). Herein we describe two clutches of eggs from $C$. major, to our knowledge the first reported description of relative clutch masses of Greater Green Snakes from Taiwan.

In September 2012, we obtained clutches of eggs (Fig. 2) from two captive Greater Green Snakes. Clutch sizes and other information pertaining to the eggs are summarized in Table 1. We made no attempts to separate bound eggs and they were weighed together. After the length, width, and weight (mass) of eggs were recorded, they were placed in an incubator with daytime temperature at ca. $28^{\circ} \mathrm{C}$ and nighttime temperature ca. $21-24^{\circ} \mathrm{C}$. We calculated relative clutch mass using the formula: (total clutch weight / mater- nal post-oviposition body weight) x 100 (Shine 1980). Mold formed on eight of the eggs, which were cleaned and isolated in the incubator from the other eggs but eventually discarded because mold continued to grow and they were spoiled. Only

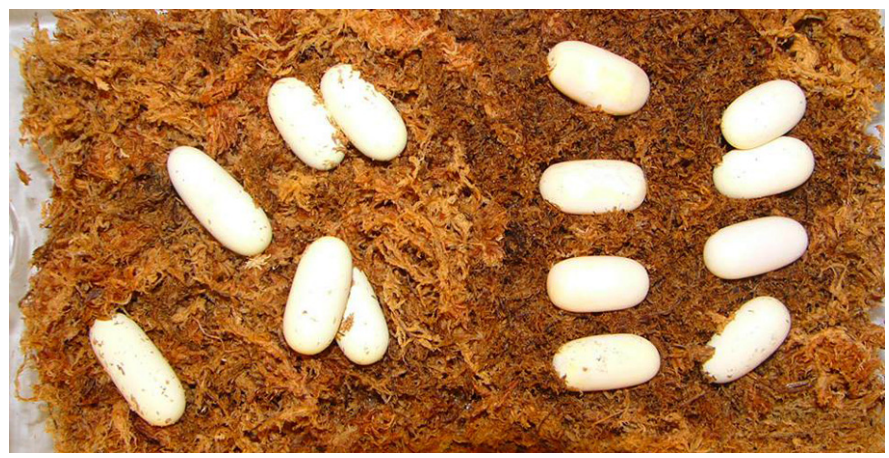

Fig. 2. The Greater Green Snake (Cyclophiops major) clutches described herein. Photograph by Simon Dieckmann.

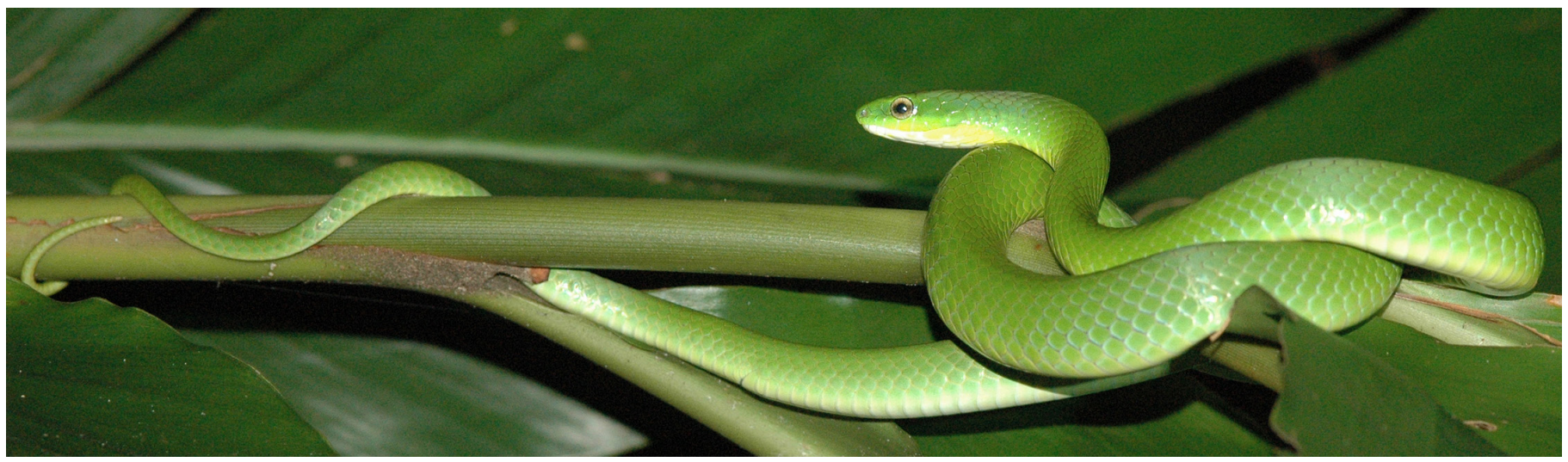

Fig. 1. Greater Green Snakes (Cyclophiops major) are fairly common on Taiwan, where they tend to inhabit grassy and wooded foothill and montane areas. Photograph by Jean-Jay Mao. 


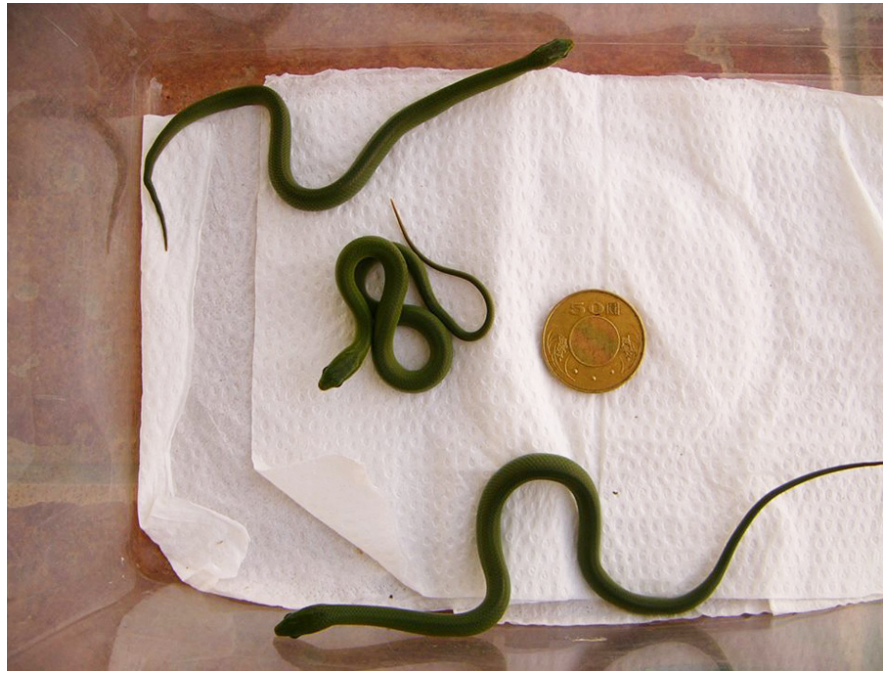

Fig. 3. The three Greater Green Snake (Cyclophiops major) hatchlings on the day they hatched. Photograph by Simon Dieckmann. three of the remaining eggs hatched. To avoid injury to the hatchlings (Fig. 3), no attempts were made to sex them, but we measured total lengths (to the nearest $\mathrm{cm}$ ) and body weights on the day they hatched and again weekly for the following three weeks in order to determine early growth rates (Table 2). Hatchlings were housed independently in small plastic animal cages ( $45 \times 25 \times 25 \mathrm{~cm}$ ), with a water bowl and a shelter; paper towels were used as substrates. We fed hatchlings every 5-7 days with small earthworms (species not determined) bought from a fishing bait store. We kept the three eggs that failed to hatch in the incubator for an additional two days, after which they were removed and dissected. All three contained fully developed dead neonates.

Understanding the natural history of a species is essential for successful conservation and management programs (Greene 1994, Bury 2006), and a crucial part of the natural history of any species is its reproductive biology. Although

Table 1. The post-oviposition body weight of the female Greater Green Snakes (Cyclophiops major), oviposition date, clutch size, relative clutch mass (RCM), and dimensions and weights of the eggs described herein. Where applicable, the mean and standard deviation are given in parenthesis (mean $\pm \mathrm{SD})$.

Female A

Post-oviposition body mass (g)

Oviposition date

Clutch size

Length (mm)

Width (mm)

Mass (g)

RCM (\%)

Incubation period

95

5 September 2012

6

$37-40(38.5 \pm 1.2)$

$14-19(16.3 \pm 1.9)$

$7-10(8.2 \pm 1.4)$

51.58

51

\section{Female B}

81

6 September 2012

8

8

Table 2. Ranges (mean and standard deviation in parenthesis) of total lengths and body weights of the hatchling Greater Green Snakes (Cyclophiops major) measured at weekly intervals.

\section{Total length $(\mathrm{cm})$}

\begin{tabular}{lll}
\hline Hatching & $17-18(17.7 \pm 0.6)$ & $3-5(4.0 \pm 1.0)$ \\
\hline $\mathbf{6}$ November 2012 & $17-18(17.7 \pm 0.6)$ & $4-7(5.3 \pm 1.5)$ \\
\hline 13 November 2012 & $17-18(17.7 \pm 0.6)$ & $5-7(6.0 \pm 1.6)$ \\
\hline 21 November 2012 & $17-19(18.3 \pm 1.2)$ & $6-7(6.3 \pm 0.6)$ \\
\hline
\end{tabular}

Table 3. A summary of references to clutch sizes and egg dimensions of Cyclophiops major.

\section{Clutch size}

\begin{tabular}{lc}
\hline June-July & $4-13(7.4 \pm 2.8)$ \\
\hline- & $4-13$ \\
\hline- & $4-13$
\end{tabular}

Egg length (mm)

$$
\text { 29-30 }
$$

-

30

Egg width (mm)

Reference

Pope 1935

Lue et al. 2002 
information from animals in captivity should be interpreted with caution, it can be incorporated with data collected from the wild to develop a better understanding of the basic biology of a species. Clutch sizes reported herein are quite similar to those reported elsewhere (Table 3). Eggs are similar in size to those reported by $\mathrm{Tu}$ (2004), but larger than those described by Pope (1935) from dissected specimens, which migh not have been fully developed or could have shrunk during preservation. The incubation period in our study is slightly shorter than the two months reported by Tu (2004). Interestingly, although hatchlings from our study are substantially shorter than those described by $\mathrm{Tu}$ (2004; total length ca. $26 \mathrm{~cm}$ ), body weights were very similar.

\section{Literature Cited}

Bury, B.R. 2006. Natural history, field ecology, conservation biology and wildlife management: Time to connect the dots. Herpetological Conservation and Biology 1:56-61.

Greene, H.W. 1994. Systematics and natural history, foundations for understanding and conserving biodiversity. American Zoologist 34:48-56.

Kuntz, R.E. 1963. Snakes of Taiwan. Quarterly Journal of Taiwan Museum 16:11-12.

Lue, K.Y., M.C. Tu, and G.S. Shang. 2002. The Transition Kingdom — Guidebook of Amphibians and Reptiles of Taiwan. Taipei, SWAN (in Chinese).

Orlov N.L., R.W. Murphy, and T.J. Papenfuss. 2000. List of snakes of Tam-Dao mountain ridge (Tonkin, Vietnam). Russian Journal of Herpetology 7:69-80.

Pope, C.H. 1935. The reptiles of China: Turtles, crocodilians, snakes, lizards. Series: Natural history of Central Asia. American Museum of Natural History 10:1-604.

Shine, R. 1980. "Costs" of reproduction in reptiles. Oecologia 46:92-100.

Tu, M.C. 2004. Big Surprise of Snakes. Yuan-Liou Publishing Co. Ltd., Taipei (in Chinese). 